\title{
ВЛИЯНИЕ ТЕХНОЛОГИЧЕСКИХ ФАКТОРОВ НА МИКРОТВЕРДОСТЬ УГЛЕЙ
}

\author{
Салтыкова Светлана Николаевна', \\ ssn_58@mail.ru
}

\author{
Назаренко Максим Юрьевич', \\ max.nazarenko@mail.ru \\ 1 Санкт-Петербургский горный университет,
Россия, 199106, Санкт-Петербург, 21-я линия В.О., 2.
}

Актуальность. Закономерная особенность в изменении твердости и прочности углей, их твердых продуктов термической переработки и брикетов на их основе заключает в себе большую теоретическую значимость, ведь данные параметры могут косвенно характеризовать свойства, связанные с особенностями происхождения углей, их петрографического состава и степени их метаморфизма.

Цель: изучение микротвердости бурых и каменных углей.

Методы: Разделение буроугольной и каменноугольной мелочи на фракции от 4 мм до менее 125 мкм осуществляли на гранулометрическом анализаторе AS Control 200. Определение влажности исследуемых объектов осуществляли в сушильном шкафу по ГОСТ 11014-2001 «Угли бурые, каменные, антрацит и горючие сланцы. Ускоренные методы определения влаги». Зольность определяли по ГОСТ 11022-95 «Топливо твердое минеральное. Определение зольности». Выход летучих веществ определялся по ГОСТ Р55660-2013 «Топливо твердое минеральное. Определение выхода летучих веществ». Брикетирование угольной и сланцевой мелочи проводилось на лабораторном гидравлическом прессе ПГЛ-20. Брикеты изготавливали при давлении 15 МПа без смачивания. Брикеты изготавливались одинаковых параметров: высота - 10 мм, диаметр 15 мм. Термообработка исследуемых брикетов осуществлялась в 2 режима: режим № 1 «Без выдержки». В муфельную печь с начальной температурой, соответствующей комнатной, помещались шесть тиглей с брикетами. Затем нагревали до $100^{\circ} \mathrm{C}$, доставали из печи один из тиглей и продолжали нагрев до $200{ }^{\circ} \mathrm{C}$. Операцию повторяли до температуры в камере печи, равной $600{ }^{\circ} \mathrm{C}$ с шагом в $100{ }^{\circ} \mathrm{C}$ без выдержки при конечной температуре; режим № 2 «Горячая печь». В нагретую до соответствующей режимной температуры (100; 200; 300; 400; 500; 600 ㄷ) муфельную печь загружали тигель с брикетом, выдерживали в течении 30 минут и вынимали. Для определения микротвердости представленных образцов использовался ультрамикротестер SHIMADZU DUH-211S для испытаний твердости (микротвердости) материалов.

Результаты. Исследование микротвердости бурых и каменных углей на брикетах из данного материала показало, что: для бурого угля при использовании обоих режимов нагревания до температуры $200^{\circ} \mathrm{C}$ значение микротвердости уменьшается С 57,928 до 44,907 H/Mм² (режим 1) и до 46,905 H/Mм² (режим 2), при увеличении температуры до $300{ }^{\circ} \mathrm{C}$ значение микротвердости начинает подниматься до 51,048 и 51,247 H/мм² для режима 1 и режима 2 соответственно. Дальнейшее нагревание приводит к увеличению значения микротвердости до 64,879 H/мм² для первого режима и уменьшению до 32,797 H/мм² для второго режима; для каменного угля при режиме термообработки № 1 значение микротвердости возрастает с 4,894 до 7,157 Н/мм², а при режиме термообработки № 2 падает до 2,921 H/мм².

\section{Ключевые слова:}

Бурые угли, каменные угли, угольная мелочь, микротвердость,

физические характеристики, механическая характеристика, термическая обработка.

\section{Введение}

Угли (бурые и каменные), сланцы и другие твердые горючие ископаемые состоят из органической части, в основе которой $\mathrm{C}, \mathrm{H}_{2}, \mathrm{~S}, \mathrm{O}_{2}, \mathrm{~N}_{2}$, и неорганической составляющей (глинистые минералы, сульфиды железа, щелочи, карбонаты, оксиды кремния и др.) Минеральные примеси и влага являются внешним балластом твердого топлива, а $\mathrm{O}_{2}$, $\mathrm{N}_{2}$ - внутренним [1-11].

Состав и содержание органической составляющей в бурых углях зависит от различных месторождений и может значительно меняться от месторождения к месторождению. Бурые угли - наименее углефицированный вид твердых горючих ископаемых в ряду углей. На горючую массу бурого угля приходится следующие процентное содержание [1-11]:

- по углероду: $\omega(\mathrm{C})=65-78 \%$;

- по водороду: $\omega(\mathrm{H})=4,3-6,3 \%$;

- по кислороду: $\omega(0)=16-27 \%$,

- по азоту: $\omega(\mathrm{N})=0,6-1,7 \%$,
- по сере: $\omega(\mathrm{S})=0,2-2,7 \%$.

Химический состав каменных углей представляет собой сложную комбинацию химических веществ. Каменный уголь включает в себя химические вещества, состоящие из углерода, водорода и кислорода. Кроме того, каменный уголь включает в себя вещества с примесями серы, азота и других элементов, содержащихся в них в небольших концентрациях. Было установлено, что вода и высокомолекулярная полициклическая ароматика являются этими веществами. Элементы, содержащиеся в небольших количествах в каменных углях, образуют минеральные соли, которые далее при термической переработке каменного угля остаются в золе. Примеси минерального происхождения распределяются в органическом веществе каменного угля либо в тонкодисперсном состоянии, либо в виде очень тонких линз и прослоек или же минеральных включений и кристаллов. Наиболее точный состав неорганических примесей определяется месторасположением каменного угля и условиями 
его образования. Химические соединения органической составляющей каменного угля представляют из себя хиноидные и фенольные соединения, а также аккумулированные бензольные кольца. На горючую массу каменного угля приходится следующее процентное содержание (\%) [4-11]:

- по углероду: $\omega(\mathrm{C})=75-92$;

- по водороду: $\omega(\mathrm{H})=2,5-5,7$;

- по кислороду: $\omega(0)=1,5-15,0$;

- по сере: $\omega(\mathrm{S})=0,2-0,6$.

При добыче, транспортировке, обогащении и переработке твердого горючего ископаемого происходит изменение его гранулометрического состава (размера зерна), которое зависит как от его физико-химических (влажность, зольность, пористость, и др.) свойств, так и от механических (хрупкость, твердость и др.). Твердость и хрупкость угольного вещества во многом определяются его химическим составом, в особенности составом минеральных составляющих, а также его структурными особенностями [8-16].

Термическое воздействие оказывает влияние на механические показатели угольных материалов: твердость и прочность, изменяя последние. По данным значениям можно оценить степень метаморфизма углей, кроме того, механические свойства способны отражать, в некотором роде, различие молекулярного строения некоторых видов горючих твердых ископаемых. Исследование твердости и прочности угля может дать также возможность найти для них техническое применение в тех или иных технологических процессах [17-19].

Свойство, которое показывает способность поверхности материала сопротивляться деформации (упругой или пластической) при внедрении в него другого, боле твердого, тела, называется твердостью. Основные методы определения данного свойства основываются либо на вдавливании жесткого наконечника (индектора) в виде шара, конуса, пирамиды и др. в испытуемое тело, либо на царапании поверхности материала эталонными образцами различной твердости.

Самым простым и быстрым способом определения такого механического свойства поверхности, как твердость (микротвердость), является вдавливание (индектирование) различного материала, которое не требует изготовления специальных эталонных образцов [17-20].

Помимо способов по определению твердости материалов широкое распространение получил способ определения микротвердости. Микротвердость - это твердость при микровдавливании. Изучение твердости на микро- и наноуровне методами инструментального индектирования сможет дать наиболее полное представление о механических свойствах твердого топлива, продуктах его переработки и брикетах на его основе, а также об особенностях его переработки [1].

Исходя из вышесказанного, целью данной работы было изучение микротвердости бурых и каменных углей.
Для достижения поставленной цели были решены следующие задачи:

- изготовлены брикеты из угольной мелочи;

- изучены физико-химические свойства используемого материала (влажность, зольность, выход летучих веществ);

- определено влияние режима термообработки на микротвердость полученных брикетов.

\section{Методы исследований}

В качестве объекта исследования была выбрана угольная мелочь (бурых и каменных углей), предварительно разделенная на фракции от 4 мм до менее 125 мкм на гранулометрическом анализаторе AS Control 200. Использовались бурые угли Канско-Ачинского бассейна и каменные угли Кузнецкого угольного бассейна следующего химического состава (табл. 1$)$.

Таблища. 1. Состав углей [4-11]

Table 1. Coal composition [4-11]

\begin{tabular}{|c|c|c|}
\hline $\begin{array}{c}\text { Kомпоненты, \% мас. } \\
\text { Component, wt. \% }\end{array}$ & $\begin{array}{c}\text { Бурый уголь } \\
\text { Brown coal }\end{array}$ & $\begin{array}{c}\text { Каменный уголь } \\
\text { Black coal }\end{array}$ \\
\hline $\mathrm{Fe}$ & 1,72 & 1,06 \\
\hline $\mathrm{S}$ & 0,23 & 1,5 \\
\hline $\mathrm{SiO}_{2}$ & 23,0 & 8,30 \\
\hline $\mathrm{CaO}$ & 1,4 & 9,98 \\
\hline $\mathrm{Al}_{2} \mathrm{O}_{3}$ & 9,4 & 1,92 \\
\hline $\mathrm{MgO}$ & 0,71 & 0,24 \\
\hline $\mathrm{C}$ & 61,0 & 77,0 \\
\hline
\end{tabular}

Определение влажности используемого материала осуществляли согласно ГОСТ 11014-2001 «Угли бурые, каменные, антрацит и горючие сланцы. Ускоренные методы определения влаги", зольность определяли согласно ГОСТ 11022-95 «Топливо твердое минеральное. Определение зольности», выход летучих веществ угольной мелочи анализировали по ГОСТ Р55660-2013 «Топливо твердое минеральное. Определение выхода летучих веществ».

Брикетирование угольной и сланцевой мелочи проводилось на лабораторном гидравлическом прессе ПГЛ-20. Брикеты изготавливали при давлении 15 МПа без смачивания. Брикеты изготавливались одинаковых параметров: высота 10 мм, диаметр 15 мм.

Термообработка исследуемых брикетов осуществлялась в два режима:

1. «Без выдержки». В муфельную печь с начальной температурой, соответствующей комнатной, помещались шесть тиглей с брикетами. Затем их нагревали до $100{ }^{\circ} \mathrm{C}$, доставали из печи один из тиглей и продолжали нагрев до 200 ${ }^{\circ} \mathrm{C}$. Операцию повторяли до температуры $600{ }^{\circ} \mathrm{C}$ в камере печи с шагом в $100{ }^{\circ} \mathrm{C}$ без выдержки при конечной температуре.

2. «Горячая печь». В нагретую муфельную печь до соответствующей режимной температуры $\left(100 ; 200 ; 300 ; 400 ; 500 ; 600{ }^{\circ} \mathrm{C}\right)$ загружали тигель с брикетом, выдерживали в течении 30 минут и вынимали. 


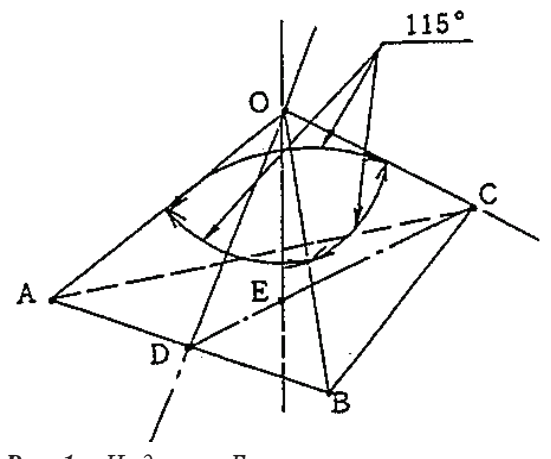

Pис. 1. Индектор Берковича

Fig. 1. Berkovich Index

Для определения микротвердости представленных образцов использовался ультрамикротестер SHIMADZU DUH-211S для испытаний твердости (микротвердости) материалов. Метод определения твердости, используемый в данной работе, соответствует стандарту ГОСТ 9450-79 «Измерение микротвердости вдавливанием алмазных наконечников» и ГОСТ Р 8.748-2011 «Металлы и сплавы. Измерение твердости и других характеристик материалов при инструментальном индектировании», что обеспечивает получение сопоставимых результатов измерения исследуемых образцов согласно требованиям стандарта ISO 14577-1 Annex A (Приложение A: свойства материалов, определяемые путем определения глубины отпечатка и силы вдавливания).

Для определения величины микротвердости использовался стандартный индектор в виде треугольной пирамиды с углом при вершине $115^{\circ}-$ индектор Берковича (рис. 1).

Образцы материала надежно закреплялись в специальной приставке. Это необходимо для того, чтобы жесткость машины не увеличивалась при испытании. Контактная поверхность между образцом и приставкой была очищена от постороннего материала, который может повлиять на измерение.

Опытным путем выбрана нагрузка $\mathrm{F}=49,0 \mathrm{mH}$. При нагрузке менее 49,0 мН невозможно рассмотреть отпечаток, оставленный индектором, а увеличение нагрузки приводит к разрушению материала. Использовался режим «нагрузка-разгрузка» со временем выдержки 5 с. Проведено по 30 контрольных испытаний на микротвердость каждого образца, и выведено среднее значение.

\section{Результаты экспериментов и обсуждение}

Исследованию механических свойств материала и влияния на него температуры должно предшествовать качественное и детальное изучение его физических свойств. Результаты анализа физических свойств (влажности, зольности и выхода летучих веществ) угля представлены в табл. 2 .

В табл. 3 представлены результаты микротвердости исходного буроугольного брикета (до термообработки). Нагрузка 49,0 мН.

Зависимость микротвердости брикета из бурого угля от температуры описана на рис. 2.
Таблица. 2. Физические свойства [12, 21]

Table 2. Physical properties [12, 21]

\begin{tabular}{|l|c|c|}
\hline \multicolumn{1}{|c|}{$\begin{array}{c}\text { Свойство } \\
\text { Property, \% }\end{array}$} & $\begin{array}{c}\text { Каменный уголь } \\
\text { Black coal }\end{array}$ & $\begin{array}{c}\text { Бурый уголь } \\
\text { Brown Coal }\end{array}$ \\
\hline Влажность/Moisture & 9,26 & 15,7 \\
\hline Зольность/Ash & 5,0 & 18,0 \\
\hline $\begin{array}{l}\text { Выход летучих веществ } \\
\text { Output of volatile substances }\end{array}$ & 29,0 & 45,0 \\
\hline
\end{tabular}

Таблица. 3. Результаты определения микротвердости буроугольного брикета

Table.3. Results of determining brown coal briquette microhardness

\begin{tabular}{|c|c|c|c|}
\hline $\begin{array}{l}\text { Максимальная } \\
\text { нагрузка } \\
\text { Maximum load }\end{array}$ & $\begin{array}{c}\text { Микротвер- } \\
\text { дость, H/мм } \\
\text { Microhardness, } \\
\text { N/mm² } \\
\end{array}$ & $\begin{array}{c}\text { Максимальная } \\
\text { нагрузка } \\
\text { Maximum load }\end{array}$ & 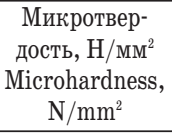 \\
\hline 49,009 & 57,761 & 49,006 & 57,745 \\
\hline 49,010 & 57,715 & 49,009 & 57,659 \\
\hline 49,008 & 58,210 & 49,007 & 58,178 \\
\hline 49,009 & 57,935 & 49,007 & 57,379 \\
\hline 49,009 & 57,737 & 49,010 & 57,907 \\
\hline 49,006 & 59,868 & 49,009 & 57,695 \\
\hline 49,009 & 57,623 & 49,006 & 57,720 \\
\hline 49,009 & 57,938 & 49,009 & 57,396 \\
\hline 49,011 & 57,339 & 49,010 & 57,109 \\
\hline 49,011 & 59,493 & 49,008 & 57,249 \\
\hline 49,008 & 57,889 & 49,011 & 57,517 \\
\hline 49,010 & 58,148 & 49,007 & 57,728 \\
\hline 49,007 & 57,680 & 49,008 & 57,469 \\
\hline 49,007 & 57,549 & 49,008 & 58,947 \\
\hline 49,007 & 57,978 & 49,010 & 59,283 \\
\hline \multicolumn{3}{|c|}{$\begin{array}{c}\text { Среднее значение микротвердости } \\
\text { Average value of microhardness }\end{array}$} & 57,928 \\
\hline
\end{tabular}

По полученным зависимостям изменение микротвердости брикета из бурого угля (рис. 2) видно следующее: при нагревании до температуры в $200{ }^{\circ} \mathrm{C}$ для обоих режимов, значение микротвердости уменьшается с 57,928 до 44,907 H/ мм $^{2}$

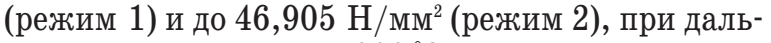
нейшем нагревании до $300{ }^{\circ} \mathrm{C}$ происходит увеличе-

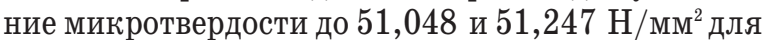
режима 1 и режима 2, соответственно. Дальнейшее нагревание приводит к увеличению значения микротвердости до $64,879 \mathrm{H} /$ мм² $^{2}$ для первого режима и уменьшению до $32,797 \mathrm{H} /$ мм $^{2}$ для второго режима. 


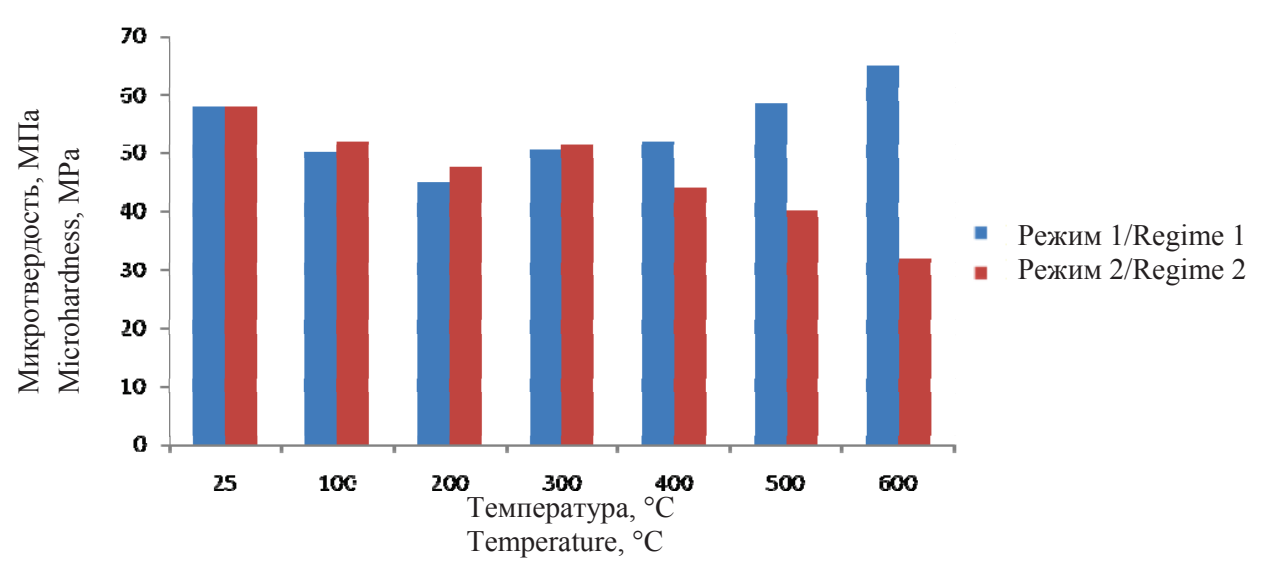

Pис. 2. Зависимость микротвердости брикета из бурого угля от температуры

Fig. 2. Dependence of brown coal briquette microhardness on temperature

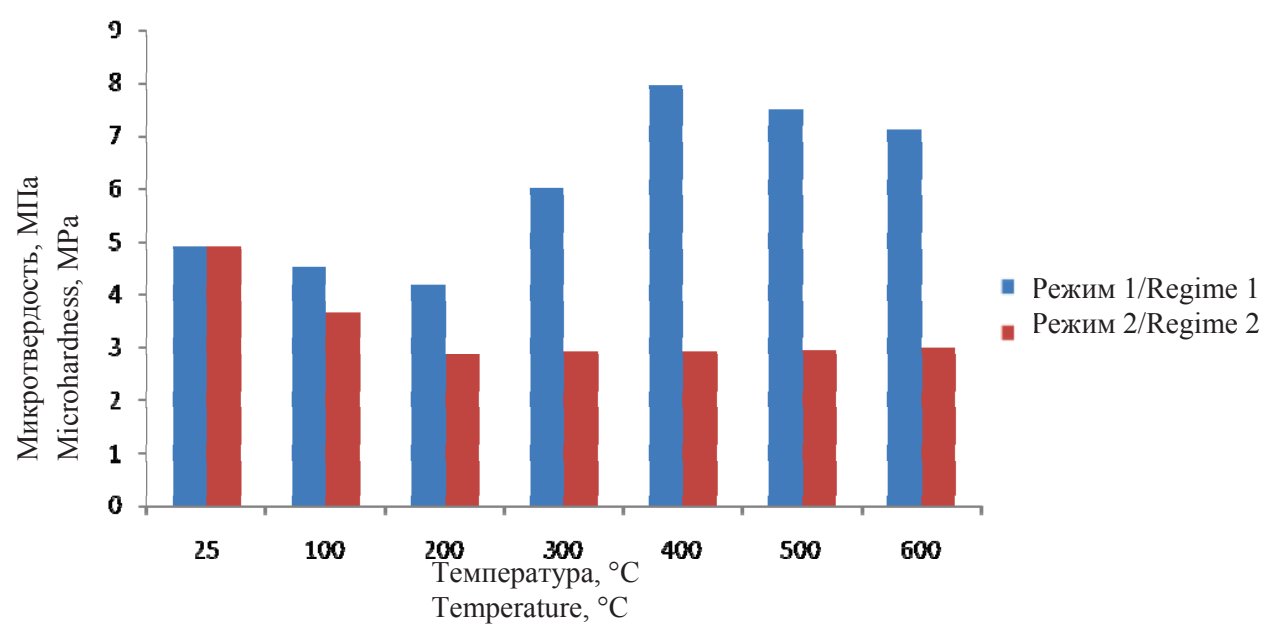

Рис. 3. Зависимость микротвердости брикета из каменного угля от температуры

Fig. 3. Dependence of coal briquette microhardness on temperature

Таблица. 4. Результаты определения микротвердости брикета из каменного угля

Table 4. Results of determining the coal briquette microhardness

\begin{tabular}{|c|c|c|c|}
\hline $\begin{array}{c}\text { Максимальная } \\
\text { нагрузка } \\
\text { Maximum load }\end{array}$ & 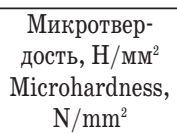 & $\begin{array}{c}\text { Максимальная } \\
\text { нагрузка } \\
\text { Maximum load }\end{array}$ & 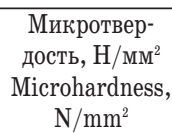 \\
\hline 49,007 & 4,887 & 49,010 & 4,327 \\
\hline 49,011 & 4,958 & 49,008 & 4,662 \\
\hline 49,010 & 5,962 & 49,008 & 5,245 \\
\hline 49,010 & 4,457 & 49,008 & 6,105 \\
\hline 49,008 & 4,394 & 49,010 & 4,7 \\
\hline 49,008 & 4,749 & 49,009 & 4,224 \\
\hline 49,008 & 4,461 & 49,009 & 4,604 \\
\hline 49,011 & 4,573 & 49,010 & 4,431 \\
\hline 49,008 & 5,619 & 49,010 & 4,198 \\
\hline 49,008 & 4,52 & 49,008 & 4,403 \\
\hline 49,008 & 5,62 & 49,010 & 5,909 \\
\hline 49,007 & 4,901 & 49,011 & 4,164 \\
\hline 49,008 & 4,257 & 49,011 & 4,783 \\
\hline 49,011 & 4,638 & 49,010 & 4,973 \\
\hline 49,011 & 5,66 & 49,009 & 6,423 \\
\hline \multicolumn{3}{|c|}{$\begin{array}{c}\text { Среднее значение микротвердости } \\
\text { Average value of microhardness }\end{array}$} & 4,894 \\
\hline
\end{tabular}

В табл. 4 представлен пример полученных результатов анализа микротвердости исходного брикета из каменного угля (до термообработки). Нагрузка 49,0 мH.

Анализ микротвердости брикета из каменного угля (рис. 3) в зависимости от температуры показал, что при режиме 1 значение микротвердости возрастает с 4,894 до $7,157 \mathrm{H} / \mathrm{мm}^{2}$, а при режиме

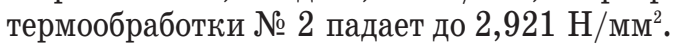

\section{Заключение}

Оценивая влияние термического воздействия на фактические показатели угольных материалов, можно дать косвенную оценку их строению и степени метаморфизма.

Исследование микротвердости бурых и каменных углей на брикетах из данного материала показало, что:

- для бурого угля до температуры $200{ }^{\circ} \mathrm{C}$ значение микротвердости для обоих режимов уменьшается с 57,928 до $44,907 \mathrm{H} / \mathrm{Mм}^{2}$ (режим 1 ) и до $46,905 \mathrm{H} / \mathrm{Mm}^{2}$ (режим 2). При нагревании до $300{ }^{\circ} \mathrm{C}$ значение микротвердости начинает под- 
ниматься до 51,048 и 51,247 Н/мм² для режима 1 и режима 2. Дальнейшее нагревание приводит к увеличению значения микротвердости до $64,879 \mathrm{H} /$ мм $^{2}$ для первого режима и уменьшению до $32,797 \mathrm{H} /$ мм $^{2}$ для второго режима;

- для каменного угля при термообработке по режиму 1 происходит рост значения микротвердости во всем диапазоне температур (с 4,894 до

\section{СПИСОК ЛИТЕРАТУРЫ}

1. Рахимова Ю.И. Профессиональная подготовка студентов по курсу «Теоретическая переработка твердого топлива». - Самара: Самарский государственный технический университет, 2011. -60 c.

2. Федорова Н.И., Михайлова Е.С., Исмагилов 3.Р. Связь теплоты сгорания углей со стадией их метаморфизма // Вестник Кузбасского государственного технического университета. 2016. - № 2. - C. 117-120.

3. Шабаров А.Н., Николаева И.В. Комплексное использование отходов переработки теплоэлектростанций // Записки Горного института. - 2016. - Т. 220. - С. 607-610.

4. Арсентьев В.А., Котова Е.Л. Новая технология сухого обогащения золы уноса угольных электростанций на основе методов прикладной минералогии // Записки Горного института. 2016. - T. 220. - C. 521-525.

5. Külaots I., Goldfarb J.L., Suuberg E.M. Characterization of Chinese, American and Estonian oil shale semicokes and their sorptive potential // Fuel. - 2010. - V. 89 (11). - P. 3300-3306.

6. Geochemistry of rare earth and other trace elements in Chinese oil shale / Q. Wang, J. Bai, J. Ge, Y.Z. Wie, S. Li // Oil shale. 2014. - V. 31. - № 3. - P. 266-277.

7. Mariana G.Y. Mineral and inorganic chemical composition of the Pernik coal // International journal of coal geology. - 2017. V. 72. - Iss. 3-4. - P. 268-292.

8. Bityukova L., Motler R. Composition of oil shale ashes from pulverized firing and circulating fluidized-bed boiler in Narva thermal power plants // Oil shale. - 2010. - V. 27. - № 4. P. 339-353.

9. Oni S.O., Olugbenda E.A., Chidimma C.N. Characterization of ash content, coking tendencies and evaluation of physicochemical properties of Okobo coals // Petroleum and coal. - 2017. V. 59 (3), - P. 397-411.

10. Ефимов В.И., Корчагина Т.В., Антонов А.И. К вопросу переработки угольных шламов // Уголь. - 2018. - № 2. - С. 77-81.

11. Eskenazy G.M., Stefanova Y.S. Trace elements in the Goze Delchew coal deposit // International journal of coal geology. 2017. - V. 72. - Iss. 3-4. - P. 257-267.
7,157 H/мм²), а при термообработке по режиму 2 происходит падение значения микротвердости до 2,921 H/ мM $^{2}$.

Работа выполнена в ралках государственного зада ния 10.12854.2018/6.7 и 10.12855.2018/8.9 «Рациональное использование и глубокая переработка углеводородного сырьл с получением судовых топлив и углеродных материалов».

12. Physicochemical properties of fuel shales / N.K. Nazarenko, V.Y. Bagin, S.N. Saltykova, G.V. Konovalov // Coke and Chemistry. - 2014. - V. 57. - № 3. - P. 129-133.

13. Alteration of the acid-base properties of the oxidized surface of disperse aluminum during the adsorption of ammonium compounds and the antifriction effect / A.G. Syrkov, M.M. Sychev, M.O. Silivanov, N.N. Rozhkova // Glass Physics and Chemistry. - 2018. - V. 44. - № 5. - P. 474-479.

14. Огирбат Пунсалмаагийн. Угольная промышленность Монголии: состояние и перспективы развития // Записки Горного института. - 2017. - Т. 226. - С. 420-427.

15. Назаренко М.Ю., Кондрашева Н.К., Салтыкова С.Н. Эффективность применения горючих сланцев и сланцезольных отходов для очистки воды от органических загрязнителей // Известия Томского политехнического университета. Инжиниринг георесурсов. - 2016. - Т. 327. - № 9. - С. 95-103.

16. Andriamihaja S., Padmamabhan E. Characterization of pore system changes induced by dissolution in carbonate rocks // Petroleum and coal. - 2017. - V. 59 (5). - P. 582-589.

17. Воздействие на структуру и свойства углей при экстремальной термообработке / В.Ю. Бажин, Ф.Ю. Шариков, Е.О. Фещенко, E.0. Судницие // Международный научно-исследовательский журнал. - 2017. - № 7. - С. 13-15.

18. Русчев Д.Д. Химия твердого топлива. - Л.: Химия, 1976. $256 \mathrm{c}$.

19. Дмитриева Г.П., Черепонова Т.С. Износостойкие кобальтовые сплавы для упрочнения бандажных полок лопаток ГТД // Texнологические системы. - 2017. -№ 2. - С. 46-49.

20. Гогоберидзе Д.Б. Твердость и методы ее измерения. - М.: Машгиз, 1952. -318 с.

21. Назаренко М.Ю., Кондрашева Н.К., Салтыкова С.Н. Влияние термических превращений в горючих сланцах на их свойства // Цветные металлы. - 2017. - № 7. - С. 29-33.

Поступила: 23.11.2018 2.

\section{Информация об авторах}

Салтыкова C.H., кандидат технических наук, доцент кафедры химических технологий и переработки энергоносителей Факультета переработки минерального сырья Санкт-Петербургского горного университета.

Назаренко М. Ю., ассистент кафедры химических технологий и переработки энергоносителей Факультета переработки минерального сырья Санкт-Петербургского горного университета. 


\title{
INFLUENCE OF TECHNOLOGICAL FACTORS ON COAL MICROHARDNESS
}

\author{
Svetlana N. Saltykova', \\ ssn58@mail.ru
}

\author{
Maxim Yu. Nazarenko', \\ max.nazarenko@mail.ru \\ 1 Saint-Petersburg Mining University, \\ 2, 21 line V.O., St-Petersburg, 199106, Russia.
}

A natural feature in changing hardness and strength of coals, their solid products of thermal processing and briquettes based on them is of great theoretical importance, because these parameters can indirectly characterize the properties associated with the characteristics of their origin, their petrographic composition and degree of their metamorphism.

The main aim of the research is to study the microhardness of brown coal and coal.

The methods. Before carrying out the experimental studies, a granulometric analysis of raw material used was carried out using a granulometric analyzer AS Control 200 with a set of sieves from $4 \mathrm{~mm}$ to less than $125 \mu \mathrm{m}$. The sample mass of $1 \mathrm{~kg}$, the amplitude of $2 \mathrm{~mm} /$ year, classification 10 minutes. Determination of humidity of the studied objects was carried out in a drying Cabinet according to SS 11014-2001 "Coals brown, stone, anthracite and oil shale. Accelerated methods of moisture determination". Ash content was determined according to SS 11022-95 «Solid mineral fuel. Determination of ash content». The yield of volatile components was determined by SS P55660-2013 "Solid mineral fuel. Determination of the yield of volatile substances». Briquetting of coal and shale fines was carried out on the laboratory hydraulic press PGL-20. Briquettes were made at a pressure of $15 \mathrm{MPa}$ without wetting. Briquettes were made of the same parameters: height $10 \mathrm{~mm}$, diameter $15 \mathrm{~mm}$. Heat treatment of the studied briquettes was carried out in two regimes: regime no. 1 "without aging». Six crucibles with briquettes were placed in the muffle furnace with the initial temperature corresponding to the room temperature. Then they were heated to $100^{\circ} \mathrm{C}$, one crucible was got out of the furnace and the rest ones were continued heating to $200{ }^{\circ} \mathrm{C}$. The operation was repeated to temperature in the furnace chamber equal to $600{ }^{\circ} \mathrm{C}$ in increments of $100{ }^{\circ} \mathrm{C}$ without exposure at the final temperature; regime no. 2 "Hot furnace». The crucible with the briquette was loaded to the muffle furnace heated to the appropriate operating temperature $\left(100 ; 200 ; 300 ; 400 ; 500 ; 600^{\circ} \mathrm{C}\right)$; it was kept there for 30 minutes and removed. To determine microhardness of the samples the ultramicrotome SHIMADZU DUH-211S was used for testing hardness (microhardness) of the material.

Results. The study of microhardness of brown coals and coal briquettes from this material showed that: for brown coal when using both heating regimes, the microhardness value decreases to a temperature of $200{ }^{\circ} \mathrm{C}$ from 57,928 to $44,907 \mathrm{~N} / \mathrm{mm}^{2}$ (regime 1) and to $46,905 \mathrm{~N} / \mathrm{mm}^{2}$ (regime 2), with temperature rise to $300^{\circ} \mathrm{C}$, the microhardness value begins to rise to 51,048 and $51,247 \mathrm{~N} / \mathrm{mm}^{2}$ for regime 1 and 2, respectively. Further heating leads to increase in microhardness to $64,879 \mathrm{~N} / \mathrm{mm}^{2}$ for the first regime and decrease to $32,797 \mathrm{~N} / \mathrm{mm}^{2}$ for the second regime; for coal in the heat treatment regime 1 microhardness value increases from 4,894 to 7,157 N/ $\mathrm{mm}^{2}$, and in the heat treatment regime 2 falls to $2,921 \mathrm{~N} / \mathrm{mm}^{2}$

\section{Key words:}

Brown coal, coal, coal fines, microhardness, physical characteristics, mechanical characteristics, heat treatment.

The research was carried out within the state tasks 10.12854.2018/6.7 and 10.12855.2018/8.9 «Rational use and deep processing of hydrocarbon raw material for obtaining marine fuels and carbon raw materials».

\section{REFERENCES}

1. Rakhimova Yu.I. Professionalnaya podgotovka studentov po kursu «Teoreticheskaya pererabotka tverdogo topliva» [Professional training of students on the course «Theoretical processing of solid fuel»]. Samara, Samara State Technical University Publ., 2011.60 p.

2. Fedorova N.I., Mikhaylova E.S., Ismagilov Z.R. Connection of the heat of combustion of coal with the stage of their metamorphism. Bulletin of the Kuzbass State Technical University journal, 2016, no. 2, pp. 117-120. In Rus.

3. Shabarov A.N., Nikolaeva I.V. Integrated use of waste from thermal power plants. Journal of Mining institute, 2016, vol. 220, pp. 607-610. In Rus.

4. Arsentev V.A., Kotova E.L. New technology of dry enrichment of fly ash of coal-fired power plants on the basis of applied Mineralogy methods. Journal of Mining institute, 2016, vol. 220, pp. 521-525. In Rus.

5. Külaots I., Goldfarb J.L., Suuberg E.M. Characterization of Chinese, American and Estonian oil shale semicokes and their sorptive potential. Fuel, 2010, vol. 89 (11), pp. 3300-3306.

6. Wang Q., Bai J., Ge J., Wie Y.Z., Li S. Geochemistry of rare earth and other trace elements in Chinese oil shale. Oil shale, 2014, vol. 31 , no. 3, pp. $266-277$.
7. Mariana G.Y. Mineral and inorganic chemical composition of the Pernik coal. International journal of coal geology, 2017, vol. 72, Iss. 3-4, pp. 268-292.

8. Bityukova L., Motler R. Composition of oil shale ashes from pulverized firing and circulating fluidized-bed boiler in Narva thermal power plants. Oil shale, 2010, vol. 27, no. 4, pp. 339-353.

9. Oni S.O., Olugbenda E.A., Chidimma C.N. Characterization of ash content, coking tendencies and evaluation of physicochemical properties of Okobo coals. Petroleum and coal, 2017, vol. 59 (3), pp. 397-411.

10. Efimov V.I., Korchagina T.V., Antonov A.I. On the issue of coal sludge processing. Russian coal journal, 2018, no. 2, pp. 77-81. In Rus.

11. Eskenazy G.M., Stefanova Y.S. Trace elements in the Goze Delchew coal deposit. International journal of coal geology, 2017, vol. 72, Iss. 3-4, pp. 257-267.

12. Nazarenko N.K., Bagin V.Y., Saltykova S.N., Konovalov G.V. Physicochemical properties of fuel shales. Coke and Chemistry, 2014, vol. 57, no. 3, pp. 129-133.

13. Syrkov A.G. Sychev M.M., Silivanov M.O., Rozhkova N.N. Alteration of the acid-base properties of the oxidized surface of disperse aluminum during the adsorption of ammonium compounds 
and the antifriction effect. Glass Physics and Chemistry, 2018, vol. 44 , no. 5, pp. 474-479.

14. Ogirbat Punsalmaagijn, Coal industry of Mongolia: state and prospects of development. Journal of Mining institute, 2017, vol. 226, pp. 420-427. In Rus.

15. Nazarenko M.Yu., Kondrasheva N.K., Saltykova S.N. Efficiency of applying oil shale and ash-shale wastes for water treatment from organic pollutants. Bulletin of the Tomsk Polytechnic University. Geo Assets Engineering, 2016, vol. 327, no. 9, pp. 95-103. In Rus.

16. Andriamihaja S., Padmamabhan E. Characterization of pore system changes induced by dissolution in carbonate rocks. Petroleum and coal, 2017, vol. 59 (5), pp. 582-589.

17. Bazhin V.Yu., Sharikov F.Yu., Feshchenko E.0., Sudnitsie E.0. Impact on the structure and properties of coal in extreme heat treatment. International research journal, 2017, no. 7, pp. 13-15. In Rus.

18. Ruschev D.D. Khimiya tverdogo topliva [Solid fuel chemistry]. Leningrad, Khimiya Publ., 1976. 256 p.

19. Dmitrieva G.P., Chereponova T.S. Wear-resistant cobalt alloys for strengthening of band flanges of GTE blades. Texnologicheskie sistemy, 2017, № 2, PP. 46-49. In Rus. Gogoberidze D.B. Tverdost i metody ee izmereniya [Hardness and methods of its measurement]. Moscow, Mashgiz Publ., 1952. 318 p.

20. Nazarenko M.Yu., Kondrasheva N.K., Saltykova S.N. Influence of thermal transformations in oil shale on their properties. Tsuetnye metally, 2017, no. 7, pp. 29-33. In Rus.

Received: 23 November 2018.

\section{Information about the authors}

Svetlana N. Saltykova, Cand. Sc., associate professor, Saint-Petersburg Mining University.

Maxim Yu. Nazarenko, assistant, Saint-Petersburg Mining University. 